\title{
A case of anaplastic liver cancer after HCV eradication with IFN-free therapy
}

\author{
Nina Nikolova, Stoyan Handzhiev, Dimitar \\ Petrov, Alexander Marinov
}

\author{
Univercity Hospital Acibadem City Clinic Oncology \\ center, Clinic of Gastroenterology
}

\begin{abstract}
Introduction

Hepatocellular carcinoma (HCC) represents more than 90\% of primary liver cancers and is a major global health problem. In the era of Direct acting agents (DAA) for treatment of hepatitis $C$ virus (HCV), sustained virological response (SVR) is achieved in more than $80 \%$ of cases. Accumulating clinical experience of DAA-based treatment has suggested that post-SVR HCC development and recurrence may be more frequent compared to interferon (IFN)-based treatment. We describe a case of poor differentiated HCC in non-cirrhotic liver, after HCV-eradication.
\end{abstract}

\section{Case presentation:}

A 73-year-old female presented with HCV-hepatitis at the beginning of 2017. A liver biopsy showed low grade fibrosis (F1). HCV genotype was 1 b, with viral load $680500 \mathrm{IU} / \mathrm{ml}$.

She was anti-HBc total positive, but negative for hepatitis B surface antigen (HBsAg) and HBV DNA negative, and also anti-HIV $1 / 2$ and had no history of alcohol or drug abuse.

In May 2017 - treatment with IFN-free regime was started - 3D - Viekirax and Exviera, without Ribavirin. At the 4th week of treatment HCV RNA was negative. At the 12th week abdominal ultrasound (US) showed a $60 \mathrm{~mm}$ liver nodule in 6th segment and a few more nodules form 10 to 32 $\mathrm{mm}$. AFP was slightly elevated $(59 \mathrm{ng} / \mathrm{ml})$. 
The contrast enhanced computed tomography (CT) scan showed typical signs of HCC. Ultra sound (US)-guided biopsy was performed. Histological result was: Anaplastic carcinoma with stromal desmoplasia and expressed lymphocyte stromal reaction (a liver origin is possible). Immunohistochemistry test showed: Alpha-feto protein - negative reaction; Ca 19-9 - negative reaction, but Ki67 - 40\% proliferative activity. The patient was at stage B according to Barcelona-clinic liver cancer (BCLC) classification and treatment with Sorafenib was started.

\section{Discussion:}

Sequence of chronic hepatitis - cirrhosis - HCC is well known. In these cases the major role in oncogenesis is due to severe fibrosis and inflammation. HCC in non-cirrhotic liver is not well understood.

The oncogenic potential of core protein of HCV has been discussed and therefore HCV is directly involved in hepatocarcinogenesis. Recent studies show higher frequency of HCC in patients with $1 b$ $\mathrm{HCV}$ infection. In presented case - the patient was infected with HCV subgenotype $1 \mathrm{~b}$ and had very low stage of fibrosis. But she was anti HBcor -positive and after HCV eradication. Several studies suggested a possibly distinct difference in host immune modulation between interferon and DAAs.

Because of multiple character of HCC (more than 3 nodule, exactly 7 in this case), the initial treatment was Sorafenib. It was well tolerated and resent CT showed only two nodules. In this stage a RFTA is discussing.

\section{Keywords: HCV, anti HBc, hepatocelullar carcinoma.}

\section{Introduction}

Liver cancer is the sixth most common cancer, the third cause of cancer-related death, and accounts for $7 \%$ of all cancers. HCC represents more than $90 \%$ of primary liver cancers and is a major global health problem. Worldwide, approximately $54 \%$ of cases can be attributed to HBV infection (which affects 400 million people globally) while $31 \%$ can be attributed to HCV infection (which affects 170 million people), leaving approximately 15\% associated with other causes (1-3). A large study analysed among 1262 patients, showed that an Anti HBC-seropositivity influence the risk of HCC in HCV infected patients compared to HCV patients without anti HBC (4).

Currently, the risk of the development of HCC in patients with HCV infection is highest in those with cirrhosis, estimated to be $2 \%$ to $8 \%$ per year in this population. The risk is noted to be lower in patients with chronic HCV infection without cirrhosis and in those who have achieved sustained virological response (SVR) $(3,1)$. Once cirrhosis is established, there is no conclusive evidence that anti-viral therapy can prevent or delay the occurrence of HCC. In fact, the risk of developing HCC continues to persist in those patients with HCV cirrhosis even after they have achieved SVR $(5,6)$ (reducing to $0.07 \%$ to $1.2 \%$ after achieving an SVR by interferon-based therapies) (7). 
In the era of Direct acting agents for treatment of HCV, SVR is achieved in more than $80 \%$ of cases $(8,9)$. Accumulating clinical experience of DAA-based treatment has suggested that post-SVR HCC development and recurrence may be more frequent compared to interferon-based treatment $(10,11)$.

Other reports do not established difference of HCC frequency between patients treated with peg-interferon plus ribavirin and direct-acting antiviral therapy $(17,18)$.

The international consensus group for hepatocellular carcinoma and the WHO propose the following classification of HCC: early HCC: a: well differentiated; b: small size $(<2 \mathrm{~cm})$; and c: poorly defined margins, vaguely nodular type; and progressed HCC: $a$ : $>2 \mathrm{~cm}$; b: small size $(<2 \mathrm{~cm})$, but moderately differentiated, distinctly nodular type $(19,20)$.

Although some authors suggest using a conventional 3-scale system, the most widely used grading system in HCC remains the 4-scale Edmondson and Steiner system from Grade well differentiated to Grade which has prominent pleomorphism and often anaplastic giant cells $(21,22)$.

We describe a case of poor differentiated HCC in non-cirrhotic liver, after HCV-eradication.

\section{Case presentation:}

A 73-year-old female presented with HCV-hepatitis at the beginning of 2017. A liver biopsy showed low grade fibrosis (F1). HCV genotype was 1b, with viral load $680500 \mathrm{IU} / \mathrm{ml}$.

The patient has a moderate arterial hypertension and Parkinson's disease.

She was anti-HBc total positive, but negative for hepatitis B surface antigen (HBsAg) and HBV DNA negative, and also anti-HIV $1 / 2$ and had no history of alcohol or drug abuse.

She have not been treatment experienced before. A videogastroscopy showed - diaphragmatic hernia and no esophageal varices.

In May 2017 - treatment with IFN-free regime was started - 3D - Viekirax and Exviera, without Ribavirin. At the 4th week of treatment HCV RNA was negative. At the 12th week abdominal ultrasound (US) showed a $60 \mathrm{~mm}$ liver nodule in 6 th segment and a few more nodules form 10 to $32 \mathrm{~mm}$. Tumor markers CEA and Ca 19-9 were in normal ranges, but AFP was slightly elevated (59 $\mathrm{ng} / \mathrm{ml})$.

The contrast enhanced computed tomography (CT) scan showed typical signs of HCC (enhanced density in arterial phase with washout in venous phase) and multiples nodules, compared to the US (in 6/7th segment the biggest nodule $-58 / 50 \mathrm{~mm}$, multiples nodules in 5, 6, 7, 8 and 4th segments in about $10 \mathrm{~mm}$, and in 2/3rd segment - one nodule $32 \mathrm{~mm}$. There was also mesenteric and retroperitoneal lymphadenomegaly. US-guided biopsy was performed with result: Anaplastic carcinoma with stromal desmoplasia and expressed lymphocyte stromal reaction (a liver origin is possible). Immunohistochemistry test showed: Alpha-feto protein - negative reaction; Ca 19-9 - negative reaction, but Ki67 - 40\% proliferative activity. The patient was at stage B according to BCLC classification. At that time she was been decided to started therapy with Sorafenib. From November 2017 a Sorafenib treatment was started. 
The last intravenous contrast enhanced CT (17May2018) showed only 2 nodules - the biggest one in $6 / 7$ th segment which was reduced (to $50 / 46 \mathrm{~mm}$ from $56 / 47 \mathrm{~mm}$ ) and nodule in 3rd segment $(24,5 / 21 \mathrm{~mm}$ from $31 / 25 \mathrm{~mm}$ ). Now a local therapy like radiofrequency termoablation (RFTA) is discussed.

\section{Discussion:}

Sequence of chronic hepatitis - cirrhosis - HCC is well known. In these cases the major role in oncogenesis is due to severe fibrosis and inflammation $(10,23)$. HCC in non-cirrhotic liver is not well understood. In about 15\%-20\% of cases HCC may occur in the non-fibrotic liver or in livers with minimal portal fibrosis without any septal fibrosis (34).

The oncogenic potential of core protein of $\mathrm{HCV}$ has been discussed and therefore $\mathrm{HCV}$ is directly involved in hepatocarcinogenesis $(23,24)$.

According to Farinati's research, $\mathrm{HCV}$ is capable of inducing this active production of free radicals per se, and it is not just through inflammation, a feature peculiar to this virus and the specific activity of its core protein (25). HCV does not integrate into the host genome the way that hepatitis B virus (HBV) does, and it does not have any proteins that have been linked to HCC (26).

Interestingly, chronic hepatitis B patients treated with directly-acting anti-HBV drugs, entecavir or other nucleos(t)ide analogues, showed higher HCC incidence compared to peg-interferon-treated patients, suggesting that the difference in $\mathrm{HCC}$-suppressive effect may be a common phenomenon across different hepatitis viruses (13). Several studies suggested a possibly distinct difference in host immune modulation between interferon and DAAs. Rapid decline of HCV viral load by DAAs was associated with restored HCVspecific, CD8+ T cell function, and normalized NK cell function $(14,15)$. Interestingly, reactivation of other co-infected viruses, such as herpes virus and HBV, was observed after DAA-based anti-HCV therapy suggesting simultaneous loss of bystander immune response to the viruses and possibly to neoplastic cells, which may lead to higher HCC recurrence after DAA treatment $(16,17)$.

Recent studies show higher frequency of HCC in patients with $1 \mathrm{~b} \mathrm{HCV}$ infection. Patients infected with HCV genotype $1 \mathrm{~b}$ have almost double the risk to develop HCC than those infected with other genotypes (Relative Risk (95\% Confidence Intervals) $=1.78(1.36-2.32)$ ) This meta-analysis suggests that HCV genotype $1 \mathrm{~b}$ plays an important role in HCC development, especially in patients with early stage liver disease (27). Our unpublished data also show higher frequency of HCC cases in patients with genotype 1b. The association between subtypes of hepatitis $\mathrm{C}$ virus (HCV) and risk of hepatocellular carcinoma remains unclear. A substitution of amino acid 70 in the hepatitis $C$ virus core region of genotype $1 \mathrm{~b}$ may be is involved in pathogenesis in these cases with $1 \mathrm{~b}$ sub genotype (28). On the other hand may be the higher viral load play a role, because participants infected with HCV 1 b had a higher mean serum HCV RNA level, than those infected with HCV non-1b (27).

In presented case - the patient was infected with HCV subgenotype $1 \mathrm{~b}$ and had very low stage of fibrosis. But she was anti HBcor -positive. More cases of anaplastic liver cancer are related to HBV infection (29). In our case we founded elevated AFP (but under $100 \mathrm{ng} / \mathrm{ml}$ ) in serum but no in immunochemistry tests. Immunohistochemistry analyze of Pang Li et al. show that in HCC patients with low serum AFP levels, immunohistochemistry still exhibited stronger AFPR staining (30). 
Expression of AFP, although observed in only about one third of the cases, favored HCC over cholangiocellular carcinoma and metastases $(31,32)$. Also the immunochemistry test showed Ki-67 activity in 40\%. With HCC and Ki-67 showed a negative correlation with histological grade $(\mathrm{P}<0.05, \mathrm{P}<$ 0.01 , respectively). Ki-67 is a nuclear antigen present only in proliferating cells. It's one of the most widely used proliferation-associated markers in cancer cells (specially in metastases). Further analysis showed that there was a close relationship between the positive rate of Ki-67 and pathological grade $(P<0.01)$ (grade 4 - Undifferentiated) (33).

In our case the patient had not advanced liver disease, she had not cirrhosis, and nodules was appeared in the end of DAA course, when HCV RNA was undetectable. Krastev et al. were described a sustained viral response (SVR) of ombitasvir/paritaprevir/ritonavir, dasabuvir and ribavirin therapy, for 12 week, in two cases with compensated liver cirrhosis and fully destroyed early hepatocellular carcinoma (HCC) (35).

Our patient was staged as B according to BCLC classification. She had a $58 \mathrm{~mm}$ liver nodule in 6th segment and a few more nodules form 10 to $32 \mathrm{~mm}$ in 5, 6, 7, 8, 2, 3 segments. Because of multifocal character of cancer and its anaplasticity, the oncology commission decided an initial treatment with Sorafenib to be started. The idea of oncology commission was in a future order to consider the destructive therapy in addition to the target therapy with Sorafenib. The treatment with Sorafenib is in range of 6 months. The last CT examination showed presence of only two lesions with reduced size - the biggest in $6 / 7$ th segment was $50 / 46 \mathrm{~mm}$ and that in $2 / 3 \mathrm{rd}$ segment was $24,5 / 21 \mathrm{~mm}$. There were no other nodules. In this stage the local therapy was discussed.

Further studies are needed to clarify whether DAAs increase HCC cases and to determine the natural history and baseline post-SVR HCC incidence according to the type of anti-HCV therapy in each specific patient population. One is clear - the routinely follow-up of patient with chronic liver disease is necessary and also obligatory, even after an eradication of the cause. But HBV genome always remains. EASL, AASLD and APASL recommend an ultrasound follow-up of 6 months periods especially in cirrhotic liver $(2,3,36)$.

In non-cirrhotic patients the surveillance period is not defined. Data from APASL guideline show a very low percent of annual cases of HCC in non-cirrhotic HBsAg carriers (0.3-0.6\%) (36). The surveillance period of non-cirrhotic patients is not exactly defined. A meta-analysis of HBsAg-negative subjects with chronic liver disease shows that anti-HBc positivity is strongly associated with the presence of HCC, an association observed in all subgroups according to the stage of the disease, etiology, and ethnicity (37). It appears that there should be a follow-up in patients with past hepatitis B infection (anti HBc positive) even without advanced liver disease. 3-6 months periods may be reasonable. 


\section{References}

1. Llovet JM, Ducreux M, Lencioni R, Di Bisceglie AM, Galle PR, Dufour JF et al. European Association for the Study of the Liver, European Organisation for Research and Treatment of Cancer clinical practice guidelines: management of hepatocellular carcinoma Journal of Hepatology 2012 vol. 56 j 908-943

2. Galle, Peter R. et al, European Association for the Study of the Liver Clinical Practice Guidelines: Management of hepatocellular carcinoma,. mars 2018 Journal of Hepatology

3. Heimbach, MD, Laura M. Kulik, MD Richard Finn, MD, Claude B. Sirlin, MD et al., American Association for the Study of the Liver diseases (AASLD) guidelines for the treatment of hepatocellular carcinoma Submitted to Hepatology for Publication January 10, 2017Julie

4. Ohki T, Tateishi R, Goto E, Sato T, Masuzaki R et al., Influence of anti-HBc seropositivity on the risk of hepatocellular carcinoma in HCV-infected patients after adjusting for confounding factors, $\mathrm{J}$ Viral Hepat. 2010 Feb 1;17(2):91-7. doi: 10.1111/j.1365-2893.2009.01152.x. Epub 2009 Jun 28

5. Nishiguchi S, Kuroki T, Nakatani S, Morimoto H, Takeda T, Nakajima S, et al. Randomised trial of effects of interferon-alpha on incidence of hepatocellular carcinoma in chronic active hepatitis C with cirrhosis. Lancet 1995;346:1051-1055.

6. Brown RS Jr. The possible association between DAA treatment for HCV infection and HCC recurrence. Gastroenterol Hepatol (N Y). 2016;12(12):776-779.

7. Bruno S, Di Marco V, lavarone M, Roffi L, Crosignani A, Calvaruso V, Aghemo A, Cabibbo G, Vigano M, Boccaccio V, et al. Survival of patients with HCV cirrhosis and sustained virologic response is similar to the general population. J Hepatol. 2016;64(6):1217-23.

8. María Buti, and Rafael Esteban, Management of direct antiviral agent failures Clinical and Molecular Hepatology 2016;22:432-438;

9. Dufour, H. Wedemeyer, D. Bernstein, Massimo Colombo, Manuel Romero-Gómez, 99.7\% Sustained Virologic Response Rate in 369 HCV Genotype 1b-Infected Pati ents Treated With Label-Recommended Regimen of Ombitasvir/Paritaprevir/r and Dasabuvir With or Without Ribavirin Presented at American College of Gastroenterology - 80th Annual Meeting, October 16-21, 2015, Honolulu, Hawaii

10. Thomas F. Baumert, Frank Jühling, Atsushi Ono, Yujin Hoshida, Hepatitis C-related hepatocellular carcinoma in the era of new generation antivirals, BMC Medicine (2017) 15:52 DOI 10.1186/s12916-017-0815-7

11. Sirisha Grandhe, MD, and Catherine T. Frenette, MD, Gastroenterology \& Hepatology Volume 13, Issue 7 July 2017; Occurrence and Recurrence of Hepatocellular Carcinoma After Successful Direct-Acting Antiviral Therapy for Patients With Chronic Hepatitis C Virus Infection

12. Liang $\mathrm{KH}$, Hsu CW, Chang ML, Chen YC, Lai MW, Yeh CT. Peginterferon is superior to nucleos(t)ide analogues for prevention of hepatocellular carcinoma in chronic hepatitis $\mathrm{B}$. J Infect Dis. 2016;213(6):966-74.

13. Martin B, Hennecke N, Lohmann V, Kayser A, Neumann-Haefelin C, Kukolj G, Bocher WO, Thimme R. Restoration of HCV-specific CD8+ T cell function by interferon-free therapy. J Hepatol. 2014;61(3):538-43.

14. Serti E, Chepa-Lotrea X, Kim YJ, Keane M, Fryzek N, Liang TJ, Ghany M, Rehermann B. Successful interferon-free therapy of chronic hepatitis $C$ virus infection normalizes natural

15. Perello MC, Fernandez-Carrillo C, Londono MC, Arias-Loste T, Hernandez-Conde M, Llerena S, Crespo J, Forns X, Calleja JL. Reactivation of herpesvirus in patients with hepatitis C treated with direct-acting antiviral agents. Clin Gastroenterol Hepatol. 2016;14(11):1662-6.e1.

16. Aggeletopoulou I, Konstantakis C, Manolakopoulos S, Triantos C. Risk of hepatitis B reactivation in patients treated with directacting antivirals for hepatitis C. World J Gastroenterol 2017; 23(24): 4317-4323 Available from: URL: http://www.wjgnet. com/1007-9327/full/v23/i24/4317.htm DOI: http://dx.doi. org/10.3748/wjg.v23.i24.4317

17. Kobayashi M1, Suzuki F1, Fujiyama S1, Kawamura Y1, Sezaki H1, Hosaka T1, Akuta N1, Suzuki Y1, Saitoh S1, Arase Y1, Ikeda K1, Kumada H1. Sustained virologic response by direct antiviral 
agents reduces the incidence of hepatocellular carcinoma in patients with HCV infection. J Med Virol. 2017 Mar;89(3):476-483. doi: 10.1002/jmv.24663. Epub 2016 Aug 23

18. Nagaoki Y, Imamura M, Aikata H, Daijo K, Teraoka Y, Honda F, et al. (2017) The risks of hepatocellular carcinoma development after HCV eradication are similar between patients treated with peg-interferon plus ribavirin and direct-acting antiviral therapy. PLoS ONE 12(8): e0182710. https://doi.org/10.1371/journal.pone.0182710

19. Sakamoto M, Hirohashi S, Tsuda H, Shimosato Y, Makuuchi M, Hosoda Y. Multicentric independent development of hepatocellularcarcinoma revealed by analysis of hepatitis $B$ virus integration pattern. Am J Surg Pathol 1989; 13: 1064-1067 [PMID: 2556944]

20. International Consensus Group for Hepatocellular NeoplasiaThe International Consensus Group for Hepatocellular Neoplasia. Pathologic diagnosis of early hepatocellular carcinoma: a report of the international consensus group for hepatocellular neoplasia. Hepatology 2009; 49: 658-664 [PMID: 19177576 DOI: 10.1002/hep.22709]

21. Schlageter M, Terracciano LM, D'Angelo S, Sorrentino P. Histopathology of hepatocellular carcinoma. World J Gastroenterol 2014; 20(43): 15955-15964

22. Paradis V. Histopathology of hepatocellular carcinoma. Re-WJG|www.wjgnet.com 15962 November 21, 2014|Volume 20|Issue 43|

23. De Oliveria Andrade LJ, D’Oliveira A, Melo RC, De Souza EC, Costa Silva CA, Paraná R. Association Between Hepatitis C and Hepatocellular Carcinoma. Journal of Global Infectious Diseases. 2009;1(1):33-37. doi:10.4103/0974-777X.52979.

24. De Mitri MS, Poussin K, Baccarini P, Pontisso P, D'Errici A, Simon N, Grigioni W, Alberti A, Beaugrand M, Pisi E, Brechot C, Paterlini P: HCV-associated liver Cancer without cirrhosis. Lancet 345: 413-415, 1995Google Scholar

25. Farinati F, Cardin R, Bortolami M, Burra P, Russo FP, Rugge M, et al. Hepatitis C virus: From oxygen free radicals to hepatocellular carcinoma. J Viral Hepat. 2007;14:821-9. [PubMed]

26. Robert S. Brown, Jr, MD, MPH, The Possible Association Between DAA Treatment for HCV Infection and HCC Recurrence, Gastroenterology \& Hepatology Volume 12, Issue 12 December 2016

27. Mei-Hsuan Lee1, Hwai-I Yang2,3,4, Sheng-Nan Lu5, Chin-Lan Jen2, San-Lin You2, Li-Yu Wang6, Gilbert L'Italien7,8,Chien-Jen Chen2,3,9, Yong Yuan7 and for the REVEAL-HCV Study Group, Hepatitis $C$ virus genotype $1 \mathrm{~b}$ increases cumulative lifetime risk of hepatocellular carcinoma, Int. J. Cancer: 135, 1119-1126 (2014) VC 2014 UICC

28. Norio Akuta, Fumitaka Suzuki,Yusuke Kawamura,Hiromi Yatsuji,Hitomi Sezaki,Yoshiyuki Suzuki,Tetsuya Hosaka, Substitution of amino acid 70 in the hepatitis C virus core region of genotype $1 \mathrm{~b}$ is an important predictor of elevated alpha-fetoprotein in patients without hepatocellular carcinoma, journal of medical Virology) Volume 80, Issue 8 August 2008, Pages 1354-1362

29. Laura D Wood; Cromophobe HCC with abrupt anaplasia: a proposal for a new subtype of HCC with unique morphological and molecular features. Modern pathology 2013, 26, 1586-1593)

30. Peng Li, Shan-Shan Wang, Hui Liu, Ning Li, Michael A McNutt, Gang Li, Hui-Guo Ding, Elevated serum alpha fetoprotein levels promote pathological progression of hepatocellular carcinoma, World J Gastroenterol 2011 November 7; 17(41): 4563-4571 ISSN 1007-9327 (print) ISSN 22192840 (online)

31. Oscar Arrieta, Bernardo Cacho, Daniela Morales-Espinosa, Ana Ruelas-Villavicencio, Diana Flores-Estrada, Norma HernándezPedro, The progressive elevation of alpha fetoprotein for the diagnosis of hepatocellular carcinoma in patients with liver cirrhosis, 8 February 2007 BMC Cancer 2007, 7:28 doi:10.1186/1471-2407-7-28

32. Bird TG, Dimitropoulou P, Turner RM, Jenks SJ, Cusack P, Hey S, et al. (2016) AlphaFetoprotein Detection of Hepatocellular Carcinoma Leads to a Standardized Analysis of Dynamic AFP to Improve Screening Based Detection. PLoS ONE 11(6): e0156801. doi:10.1371/journal.pone.0156801 
33. Wei Shi1, Jiangfeng Hu, Shizhang Zhu, Xiaoying Shen, Xiaoyan Zhang, Changqing Yang, Hengjun Gao, Hao Zhang, Expression of MTA2 and Ki-67 in hepatocellular carcinoma and their correlation with prognosis Int J Clin Exp Pathol 2015;8(10):13083-13089

34. Schlageter M, Terracciano LM, D'Angelo S, Sorrentino P. Histopathology of hepatocellular carcinoma. World J Gastroenterol 2014; 20(43): 15955-15964 Available from: URL: http://www. wjgnet.com/1007-9327/full/v20/i43/15955.htm DOI: http:// dx.doi.org/10.3748/wjg.v20.i43.15955

35. Krastev Z, Jelev D, Antonov K, Petkova T, Atanasova E, Zheleva N, Tomov B, Boyanova Y, Mateva L, Ombitasvir, paritaprevir, ritonavir, dasabuvir and ribavirin in cirrhosis after complete destruction of hepatocellular carcinoma, World J Gastroenterol 2016 February 28; 22(8): 26302635 ISSN 1007-9327 (print) ISSN 2219-2840 (online)

36. Masao Omata, Ann-Lii Cheng, Norihir Kokudo, Masatoshi Kudo, Jeong Min Lee et al., AsiaPacific clinical practice guidelines on the management of hepatocellular carcinoma: a 2017 update, Hepatol Int (2017) 11:317-370 DOI 10.1007/s12072-017-9799-9

37. Nicola Coppola, MD, PhDa,*, Lorenzo Onorato, MDa, Caterina Sagnelli, MD, PhDb, Evangelista Sagnelli, MDa, Italo F. Angelillo, DDS, MPHc Association between anti-HBc positivity and hepatocellular carcinoma in HBsAg-negative subjects with chronic liver disease A meta-analysis (Medicine 2016).

\section{Corresponding author:}

Nina Nikolova,

Univercity Hospital Acibadem City Clinic

Oncology center,

Clinic of Gastroenterology

email: nnikolova234@gmail.com 